\title{
Hypertrophic obstructive cardiomyopathy: the Mayo Clinic experience
}

\author{
Kunal D. Kotkar, Sameh M. Said, Joseph A. Dearani, Hartzell V. Schaff \\ Department of Cardiovascular Surgery, Mayo Clinic, Rochester, MN, USA \\ Correspondence to: Sameh M. Said, MD. Department of Cardiovascular Surgery, Mayo Clinic, $2001^{\text {st }}$ St SW, Rochester, MN 55905, USA. \\ Email: said.sameh@mayo.edu.
}

Background: Hypertrophic cardiomyopathy (HCM) is a primary myocardial disease characterized by left ventricular hypertrophy in the absence of other etiologies. Clinical presentation may vary from asymptomatic to sudden cardiac death. Medical treatment is the first-line therapy for symptomatic patients. Extended left ventricular septal myectomy is the procedure of choice if medical treatment is unsuccessful or intolerable.

Mayo Clinic experience: More than 3,000 patients have had septal myectomy for HCM at the Mayo Clinic (MN, USA) from 1993 to 2016. Risk of hospital death after isolated septal myectomy for obstructive $\mathrm{HCM}$ is $<1 \%$ and is similar to the risk of operation for elective mitral valve repair. Complications, such as complete heart block requiring permanent pacemaker, are uncommon (2\%), although partial or complete left bundle branch block is a frequent finding on the postoperative ECG. Relief of left ventricular outflow tract (LVOT) obstruction with septal myectomy dramatically improves symptoms and exercise capacity in symptomatic patients with obstructive HCM. More than $90 \%$ of severely symptomatic patients have improvement by at least two functional classes, and reduction of outflow gradients by myectomy decreases or eliminates symptoms of dyspnea, angina and/or syncope. Basal obstruction with systolic anterior motion (SAM) is treated by transaortic myectomy. The transapical approach was applied in 115 patients with obstructive midventricular and apical variants of HCM between 1993 and 2012. All patients with midventricular obstruction had gradient relief and none developed an apical aneurysm or ventricular septal defect. Recurrent obstruction after satisfactory myectomy was rare.

Conclusions: Septal myectomy effectively and definitively relieves LVOT obstruction and cardiac symptoms in patients with obstructive HCM. In experienced centers, early mortality for isolated septal myectomy is less than $1 \%$, and overall results are excellent and continue to improve in the current era.

Keywords: Hypertrophic cardiomyopathy (HCM); septal myectomy; systolic anterior motion (SAM)

Submitted Mar 01, 2017. Accepted for publication Apr 27, 2017.

doi: $10.21037 /$ acs.2017.07.03

View this article at: http://dx.doi.org/10.21037/acs.2017.07.03

\section{Introduction}

Hypertrophic cardiomyopathy (HCM) is a primary myocardial disease characterized by left ventricular hypertrophy in the absence of other etiologies such as aortic valve stenosis or systemic arterial hypertension. Morphology is variable, common variants being basal, mid-ventricular, apical, and diffuse types (Figure 1). HCM has different presentations, from asymptomatic to sudden cardiac death. The pathophysiology in obstructive HCM is systolic anterior motion (SAM) of the anterior leaflet of the mitral valve, which adds to the LVOT obstruction and may lead to various degrees of mitral valve regurgitation, further exacerbating the symptomatology. Medical treatment is the first-line therapy for symptomatic patients with LVOT obstruction (1); however, extended left ventricular septal myectomy is the procedure of choice if medical treatment is unsuccessful or intolerable (2).

In this article, we will discuss the surgical management of hypertrophic cardiomyopathy at the Mayo clinic under the following headings: 


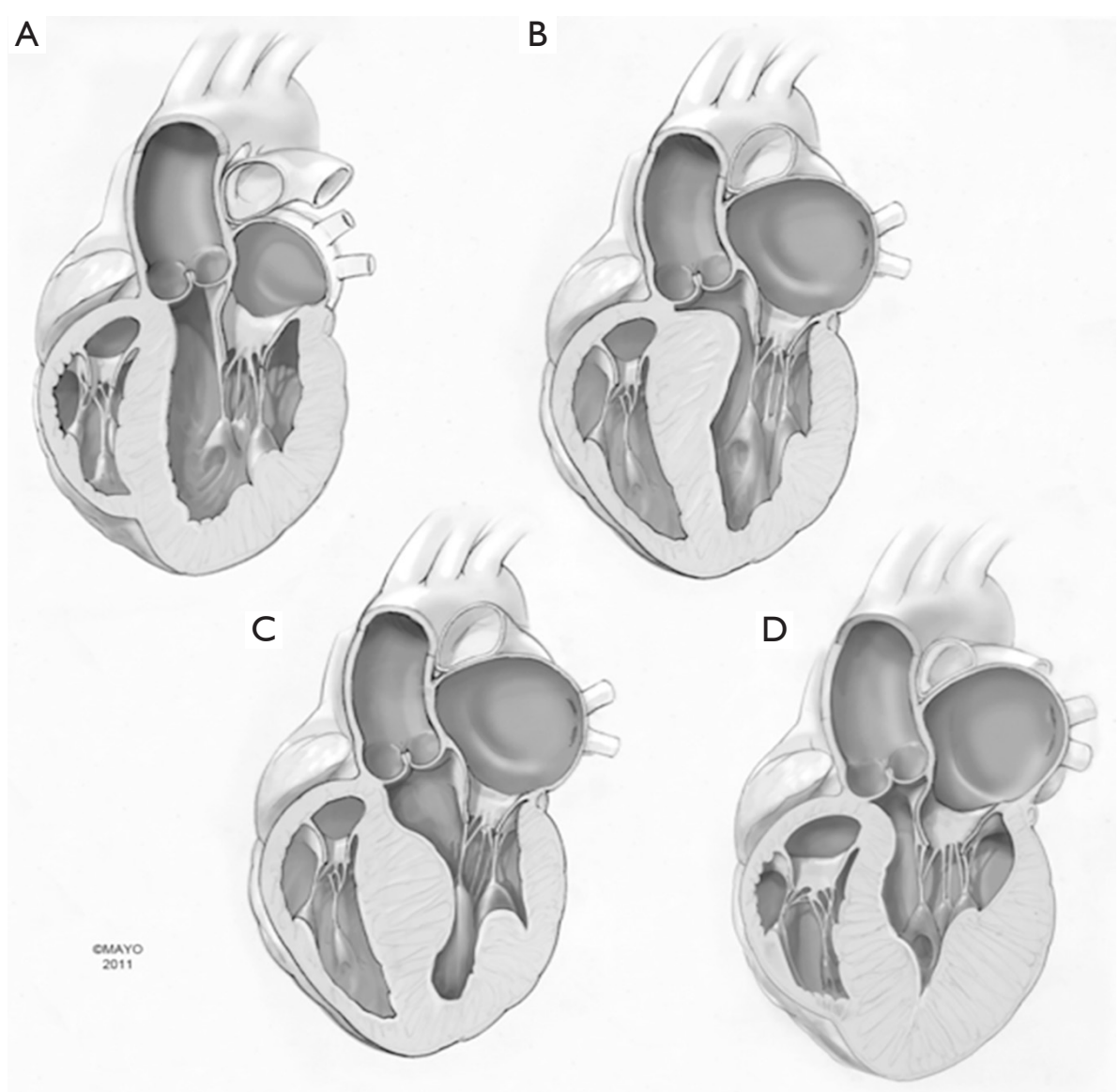

Figure 1 Variants of hypertrophic cardiomyopathy. (A) Normal heart and the different morphologic types of hypertrophic cardiomyopathy: (B) basal, (C) midventricular and (D) apical.

(I) Current indications for septal myectomy;

(II) Adjuncts to septal myectomy:

(i) Arrhythmia surgery

(ii) Management of papillary muscle abnormalities

(iii) Management of concomitant mitral valve disease

(III) Septal myectomy versus alcohol septal ablation;

(IV) Septal myectomy after alcohol septal ablation;

(V) Other indications for septal myectomy:

(i) Management of apical and midventricular variants

(ii) Management of pediatric HCM

(iii) The phenomenon of latent obstruction

(iv) Recurrent outflow tract obstruction after prior septal myectomy

(VI) Outcomes of septal myectomy at the Mayo Clinic.

\section{Current indications for septal myectomy}

The standard indications for septal myectomy are symptoms refractory to medical treatment combined with severe LVOT obstruction with resting gradient of more than $30 \mathrm{mmHg}$; however, the current indications have expanded recently to include symptomatic patients with low resting outflow gradients and latent obstruction. In addition, our experience suggests that a subgroup of patients with favorable septal anatomy have particularly positive outcomes and might be considered for operation without a prolonged trial of medical treatment (3).

\section{Adjuncts to septal myectomy}

\section{Arrhythmia surgery}

Patients with HCM are at increased risk of atrial fibrillation (AF) secondary to long-standing elevation of the left ventricular end-diastolic and left atrial pressures with subsequent left atrial chamber enlargement. Currently, 


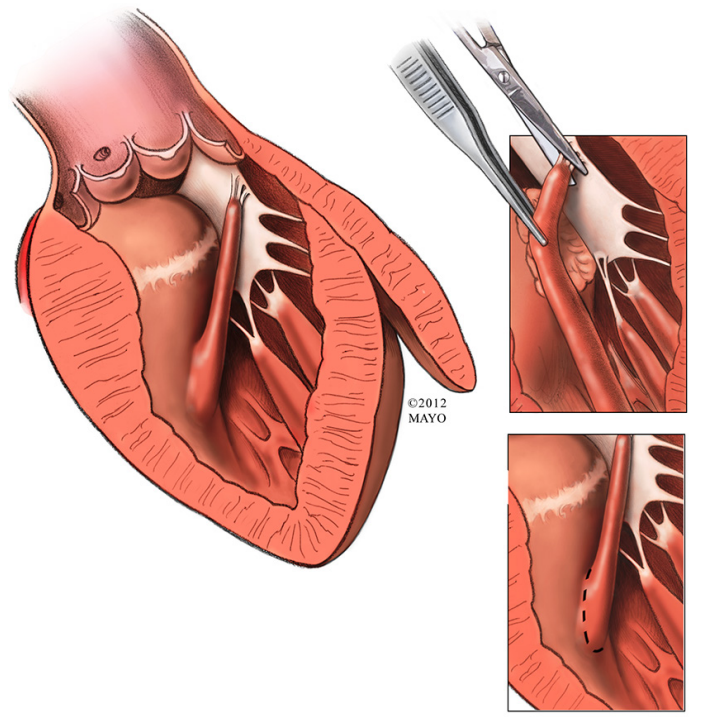

Figure 2 Accessory papillary muscle that arises from the ventricular septum and is attached to the side of the anterior leaflet. This accessory muscle is excised in its entirety; the fibrous attachments to the side of the leaflet are cut and the papillary muscle is amputated at its base and removed (dotted line). Chordal attachments to the leading edge of the anterior leaflet are preserved.

there is little evidence to support the addition of the Coxmaze procedure to septal myectomy; however, our current strategy is to perform concomitant arrhythmia surgery at the time of septal myectomy in the presence of AF. Early results have demonstrated the feasibility of such an approach with no mortality and a higher rate of maintenance of sinus rhythm (4). The type of arrhythmia (Maze) surgery that is best suited for patients with HCM is controversial. In general, we perform pulmonary vein isolation with excision of the left atrial appendage for those with paroxysmal AF; and for those with permanent/persistent AF and severely enlarged left atrium, we prefer bi-atrial Cox-Maze III procedure (cut and sew) or Cox-Maze IV.

\section{Management of papillary muscle abnormalities}

Anomalies of the mitral valve apparatus exist in some patients with obstructive HCM and can lead to persistent LVOT obstruction after septal myectomy $(5,6)$. Anomalous papillary muscle insertion into the body of the anterior mitral leaflet (Figure 2) is a well-recognized entity and its diagnosis may be challenging even for the experienced cardiologist (7). An understanding of these mitral valve abnormalities with adjunctive maneuvers being applied at

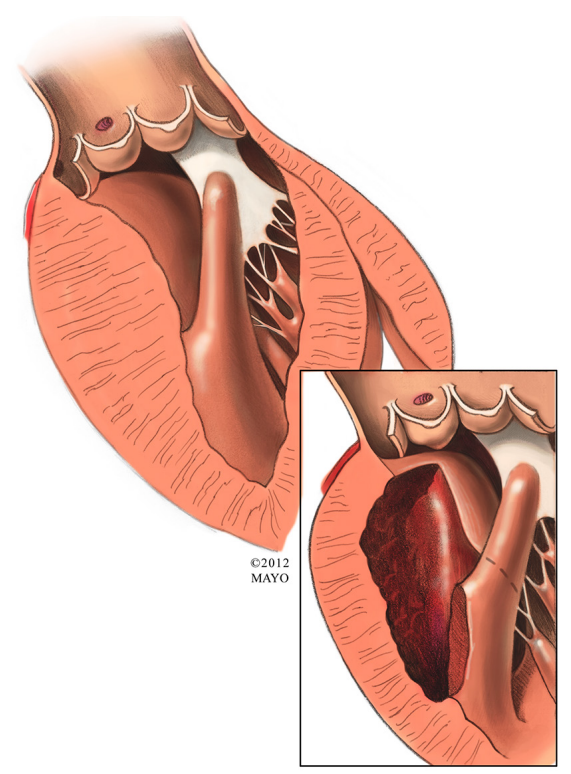

Figure 3 Direct insertion of the head of the anterolateral papillary muscle into the anterior leaflet of the mitral valve with concomitant fusion to the left ventricular septum and free wall. The papillary muscle is incised off the left ventricular septum and free wall down to its base (inset) in addition to performing an extended myectomy.

the time of extended myectomy can achieve excellent relief of LVOT obstruction with preservation of the native mitral valve function (8). This may require concomitant resection or mobilization of the anomalous papillary muscle(s) if present to ensure complete relief of the LVOT gradient.

Other anomalies of the mitral apparatus include fusion of the anterior papillary muscle with the ventricular septum or left-ventricular free wall (Figure 3), abnormal chordae tendineae (false chordae) that attach to the ventricular septum or free wall (Figure 4) and accessory papillary muscles, all of which may tether the mitral leaflets towards the septum (and outflow tract) and contribute to a persistent LVOT gradient. Severely hypertrophied papillary muscles or exaggerated anterior displacement of the anterolateral papillary muscle can lead to obstruction at both the outflow tract level as well as the midventricular level (9). The surgical principle of treatment is to divide attachments (fibrous or muscular) between the subvalvar apparatus and septum or free wall, and to preserve all attachments to the leading edge of the anterior leaflet to avoid iatrogenic mitral valve incompetence.

\section{Management of concomitant mitral valve disease}

Management of structural mitral valve disease requires 


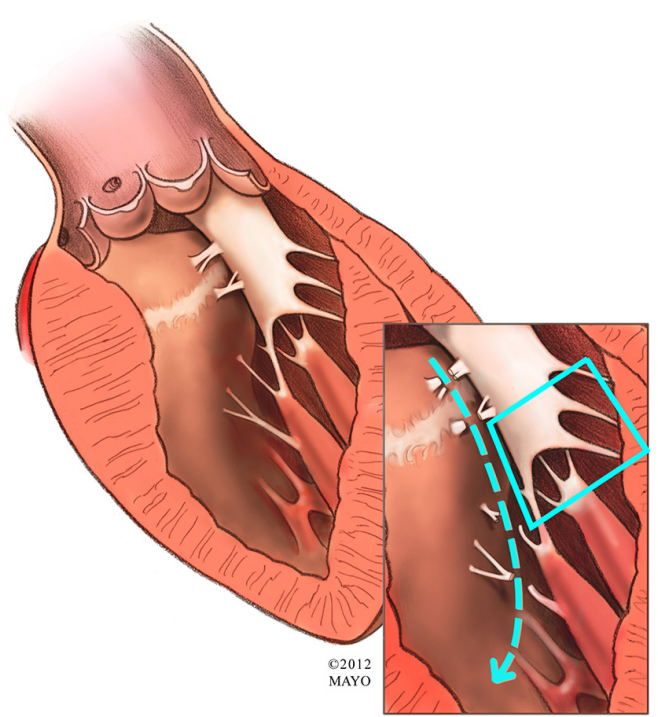

Figure 4 Fibrous attachments between the side of the anterior mitral leaflet and the ventricular septum or free wall. We maintain all attachments that come to the leading edge of the anterior mitral leaflet.

special attention in the setting of obstructive HCM. Specifically, structural abnormalities of the mitral valve require attention at the time of myectomy in contrast to SAM-mediated MR that typically resolves with extended myectomy alone. We perform leaflet resection for posterior leaflet prolapse or flail, and use artificial (GORE-TEX ${ }^{\circledR}$ ) chordae for unsupported anterior leaflet abnormalities. The choice to use a flexible posterior band is individualized, and when a band is utilized, we slightly upsize it to minimize or avoid potential development of SAM postoperatively (10).

We reviewed an initial experience with 32 patients between 1990 and 2006 (11), who underwent combined septal myectomy and mitral valve repair for degenerative mitral valve disease. Repair techniques included leaflet resection in ten patients, edge-to-edge repair in six patients, leaflet plication in eight, and annuloplasty band/ring in 19 patients. There was one early death (3\%) and the gradient across the LVOT was reduced from $63.7 \pm 37.6 \mathrm{mmHg}$ preoperatively to $10.2 \pm 19.0 \mathrm{mmHg}$ at discharge. Upon discharge, mild or no mitral valve regurgitation was present in 21 patients, while six patients had mild to residual moderate mitral regurgitation.

\section{Alcohol septal ablation versus septal myectomy}

Extended left ventricular septal myectomy is considered the gold standard for managing symptomatic patients with obstructive variants of HCM (12). Catheter-based alcohol septal ablation (ASA) to create a septal infarction has emerged as a percutaneous alternative to surgical septal myectomy $(13,14)$. Both procedures can result in improvement of LVOT gradient, obstruction relief and improvement in heart failure symptoms, and importantly, both procedures are operator dependent. However, the literature tends to support better long-term symptom relief in those patients who undergo septal myectomy (15). It is important to recognize that procedural success is higher, and rate of complications lower, when myectomy is performed in experienced centers compared with alcohol septal ablation $(13,16)$.

We have previously published results of alcohol septal ablation in 138 patients with HCM who underwent such procedures between 1998 and 2006. The mortality and morbidity of the procedure were higher for ASA compared with an age- and gender-matched population who underwent septal myectomy at the Mayo Clinic (17). Septal myectomy in patients of 65 years of age or less also had significantly better survival and freedom from severe symptoms $(\mathrm{P}=0.01)$.

There are certain subsets of patients with HCM that are not candidates for alcohol septal ablation. Poor candidates for ASA include young patients, those with severe (diffuse) or relatively thin septal thickness and a very high LVOT gradient (13). A major advantage of septal myectomy over ASA is the immediate results, immediate reduction in LVOT gradient (18), and the lack of potential longterm ventricular arrhythmias that are more likely with ASA and that may cause septal infarction. Importantly, septal myectomy also facilitates the correction of other abnormalities of the outflow tract and repair of associated abnormalities of the mitral valve and anomalous papillary muscles that can also contribute to residual dynamic outflow tract obstruction. These issues emphasize the importance of a careful preoperative echocardiogram that can identify abnormalities such as discrete subaortic stenosis, mitral valve defects (ruptured chordae), and anomalous papillary muscles in a patient being evaluated for presumed obstructive HCM and who would not respond to the ASA approach.

\section{Septal myectomy after alcohol septal ablation}

An increasing number of patients may present with recurrent symptoms secondary to LVOT obstruction that persists following ASA and requires reintervention (19).

Alcohol septal infarction frequently results in a right 
bundle branch block or complete heart block that requires permanent pacing. In addition, septal myectomy often results in a left bundle branch block. Subsequently, when myectomy follows an unsuccessful ASA, permanent pacing is often required postoperatively. We have experience with approximately 40 patients that underwent myectomy following ASA to date. Prior experience with 16 patients who underwent 22 prior septal artery ablations between 1999 and 2006 has been reported previously. Results demonstrate slightly higher early mortality and perioperative morbidity, including higher chance of permanent pacemaker secondary to heart block, despite successful relief of the outflow tract gradient (20).

\section{Other indications for septal myectomy}

\section{Management of apical \& midventricular variants}

Apical and midventricular variants of HCM are difficult entities to diagnose and treat medically, with the only alternative to myectomy being heart transplantation. There are two situations when the transapical approach is most appropriate (21). This includes midventricular obstruction that cannot be reached by a transaortic approach alone; this subgroup typically does not have SAM and the gradient is identified in the midventricle opposite the papillary muscles. Resection of midventricular obstruction is accomplished by an isolated transapical incision or a combined transaortic and transapical approach. The second subgroup is the nonobstructive apical morphology that results in a small left ventricular cavity, diastolic dysfunction and "below normal" stroke volume. This physiology also results in refractory heart failure symptoms similar to the obstructive variants. The purpose of apical myectomy in this group is to increase the left ventricular end diastolic and systolic dimensions, which will result in an increase in stroke volume into the normal range. Heart failure symptoms in the nonobstructive category are also abolished with this approach.

\section{Management of pediatric HCM}

Pediatric HCM can cause significant outflow tract obstruction and symptoms of heart failure. It is one of the most common causes of sudden death in young people (13). Medical treatment and indications for surgery are generally the same as the adult population; however, symptoms are more commonly absent in the child, which makes the timing of myectomy more difficult. In addition, myectomy is more challenging in children because of smaller structures (aortic root) and, consequently, incomplete myectomy or aortic or mitral valve injury is more likely than in the adult population. The overall prognosis of HCM in the pediatric population has been shown to be less favorable than for adults $(22,23)$. However, in our experience, septal myectomy remains safe and effective in symptomatic children and late survival is better than in the previously published untreated natural history of HCM in children (24).

Our experience with myectomy in children approaches 200 consecutive patients. We previously published our experience (24) with 127 consecutive children and young adults ( $<21$ years of age; $62 \%$ male) who underwent transaortic septal myectomy for obstructive HCM from January 1975 to December 2010. The mean age at operation was $12.9 \pm 5.5$ years. Preoperatively, mean maximum instantaneous gradient was $89 \mathrm{mmHg}$ and 95\% had significant SAM with mitral regurgitation. An implantable cardioverter-defibrillator (ICD) and permanent pacemaker prior to surgery was present in $21(17 \%)$ and 15 (11.7\%) patients, respectively.

Transaortic extended left ventricular septal myectomy was performed in all patients with no early deaths. Iatrogenic morbidity included new aortic valve regurgitation requiring repair in seven patients $(5.5 \%)$, mitral regurgitation (MR) needing repair in two patients $(1.5 \%)$, ventricular septal defect in one patient $(1 \%)$ and heart block requiring permanent pacemaker in one patient (1\%). An ICD was inserted postoperatively in eight patients during the same hospital admission. Mean maximum gradient decreased from 89 to $6 \mathrm{mmHg}(\mathrm{P}<0.0001)$. Postoperatively, residual chordal SAM was present in $23 \%$ with mild or no MR; moderate MR was detected in only one patient. Four patients (3\%) died late during the mean follow-up period of 8.3 years (max: 37 years); one death was sudden. Overall survival was $98.6 \%, 94.9 \%, 92.4 \%$ and $92.4 \%$ at 5,10 , 15 and 20 years, respectively. Freedom from any cardiac reoperation was $91.2 \%, 87.8 \%, 78.7 \%$ and $72.7 \%$ at 5,10 , 15 and 20 years, respectively. Repeat septal myectomy was performed in six patients (5\%). At late follow-up, $95 \%$ were in NYHA functional class I or II, and 25 patients underwent late ICD placement. Patient selection and surgical expertise remain critical components for the success of septal myectomy in the pediatric population.

\section{The phenomenon of latent obstruction}

There is a group of patients with HCM that are 
symptomatic despite a low resting LVOT gradient and it can be unclear whether their symptoms are due to diastolic dysfunction or a labile outflow tract gradient (25). We reviewed our experience with 249 patients with latent obstruction $(0-30 \mathrm{mmHg}$ resting gradient) but with evidence of severe LVOTO when provoked by Valsalva maneuver or amyl nitrite inhalation during Doppler echocardiography. This group was compared with those who had severe resting gradient $(>30 \mathrm{mmHg})$ and underwent myectomy during the same time period. Early mortality was similarly low (1\%) and long-term survival was comparable with an age-matched population. We concluded that these patients should be offered surgical septal myectomy despite their low resting gradient, since it appears that their symptoms are more related to their latent form of obstruction rather than diastolic dysfunction, and early and late results are favorable.

\section{Recurrent outflow tract obstruction after prior septal myectomy}

Despite the excellent results of septal myectomy in relieving the LVOT gradient, there is a small group of patients who undergo septal myectomy and present with recurrent symptoms of outflow tract obstruction. In general, this is more often related to inadequate relief of obstruction (i.e., incomplete myectomy) at the initial operation as opposed to recurrent growth of muscle during the follow-up period. This is particularly noted in children who appear to be at higher risk of having such recurrence (26). The small nature of the aortic root can predispose to inadequate myectomy; the cause of incomplete myectomy is most often due to inadequate muscle resection at the midventricular level (i.e., the apical extent of resection) and is frequently related to surgeon inexperience. This is also often the case in the adult population. Our current experience with redo myectomy now includes approximately 50 patients. We reported our initial experience of 13 patients between 1975 and 2003 who underwent repeat septal myectomy (27). Age ranged from 4 to 70 years and the interval between the initial and repeat myectomy ranged from 13 months to 11 years. We identified the following mechanisms of recurrent LVOTO: limited initial myectomy in 11 patients, septal hypertrophy at the midventricular level in eight and anomalous papillary muscle in three patients. There was only one death during late follow-up and all patients had excellent symptom relief. Repeat septal myectomy is feasible and should be offered to symptomatic patients with dynamic outflow tract obstruction.

\section{Outcomes of septal myectomy at the Mayo clinic}

More than 3,000 patients have had septal myectomy for HCM at the Mayo Clinic (MN, USA) from 1993 to 2016. Risk of hospital death after isolated septal myectomy for obstructive HCM was $<1 \%$ and is similar to the risk of operation for elective mitral valve repair. Complications such as iatrogenic ventricular septal defect was rare $(<0.3 \%)$. Complete heart block requiring permanent pacemaker was uncommon (2\%), although partial or complete left bundle branch block was a frequent finding on the postoperative ECG. Usually, this is not associated with adverse sequelae, but if the patient has complete right bundle branch block preoperatively, the left bundle branch block after myectomy increases the risk of complete heart block and the need for permanent pacing. This is particularly important in patients who have had alcohol septal ablation preoperatively, which leads to right bundle branch block in up to $60 \%$ of patients (28). Relief of LVOT obstruction with septal myectomy dramatically improves symptoms and exercise capacity in symptomatic patients with obstructive HCM. Approximately $90 \%$ of severely symptomatic patients have improvement of at least two functional classes and relief of outflow gradients by myectomy is equally effective in improving limitations caused by dyspnea, angina or syncope (29). Importantly, symptomatic benefit of myectomy is related directly to reducing the basal outflow obstruction, MR and improving left ventricular systolic and end-diastolic pressures (in more than $90 \%$ of patients), which in turn may also favorably influence myocardial ischemia.

Relief of the gradient may decrease left atrial size and the subsequent risk of developing AF. Importantly, the late survival is equivalent to an age-matched population and the risk of appropriate ICD discharges decreases significantly after abolishment of the gradient.

We have used the transapical approach in a total of 115 patients with midventricular and apical variants of HCM between 1993 and 2012. All patients with midventricular obstruction ( $\mathrm{n}=55)$ had gradient relief and none developed a ventricular septal defect. In addition, we have not observed complications from the left ventriculotomy such as left ventricular apical aneurysm or ventricular arrhythmias. The apical incision and its closure produce an area of akinesis, 
but this is relatively small and does not lead to significant systolic dysfunction. Indeed, in patients with apical HCM, the apex is obliterated with muscle and does not contribute to LV stroke volume (30).

\section{Summary}

Septal myectomy is the most effective treatment of LVOT obstruction and cardiac symptoms in adults and children with obstructive HCM. In experienced centers, early mortality for isolated septal myectomy is less than $1 \%$ and overall results are excellent and continue to improve in the current era. Late recurrence of significant resting left ventricular outflow gradients is very uncommon after successful myectomy and complete elimination of the gradient in both adults and children with obstructive HCM. Recurrent LVOT obstruction and symptoms may occur due to inadequate myectomy at the first operation, midventricular obstruction or anomalies of mitral valve and papillary muscles. Lifelong medical surveillance is important in all patients despite good surgical results.

\section{Acknowledgements}

None.

\section{Footnote}

Conflicts of Interest: The authors have no conflicts of interest to declare.

\section{References}

1. Gersh BJ, Maron BJ, Bonow RO, et al. 2011 CCF/AHA guideline for the diagnosis and treatment of hypertrophic cardiomyopathy: executive summary: a report of the American College of Cardiology foundation/American Heart Association Task Force on Practice Guidelines. J Thorac Cardiovasc Surg 2011;142:1303-38.

2. Nishimura RA, Giuliani ER, Brandenburg RO, et al. Chapter 20: Hypertrophic cardiomyopathy. In: Giuliani ER, Gersh BJ, McGoon MD, et al. editors. Myocardial Disease: Mayo Clinic Practice of Cardiology, 3rd ed. St. Louis, MO: Mosby-Year Book, 1996:689-711.

3. Said SM, Dearani JA, Ommen SR, et al. Surgical treatment of hypertrophic cardiomyopathy. Expert Rev Cardiovasc Ther 2013;11:617-627.

4. Chen MS, McCarthy PM, Lever HM, et al. Effectiveness of atrial fibrillation surgery in patients with hypertrophic cardiomyopathy. Am J Cardiol 2004;93:373-5

5. Cape EG, Simons D, Jimoh A, et al. Chordal geometry determines the shape and extent of systolic anterior mitral motion: in vitro studies. J Am Coll Cardiol 1989;13:1438-48.

6. Klues HG, Roberts WC, Maron BJ. Anomalous insertion of papillary muscle directly into anterior mitral leaflet in hypertrophic cardiomyopathy. Significance in producing left ventricular outflow obstruction. Circulation 1991;84:1188-97.

7. Yang HS, Lee KS, Chaliki HP et al. Anomalous insertion of the papillary muscle causing left ventricular outflow obstruction: visualization by real-time three-dimensional echocardiography. Eur J Echocardiogr 2008;9:855-60.

8. Maron BJ, Nishimura RA, Danielson GK. Pitfalls in clinical recognition and a novel operative approach for hypertrophic cardiomyopathy with severe outflow obstruction due to anomalous papillary muscle. Circulation 1998;98:2505-8.

9. Reis RL, Bolton MR, King JF, et al. Anterior-superior displacement of papillary muscles producing obstruction and mitral regurgitation in idiopathic hypertrophic subaortic stenosis - operative relief by posterior-superior realignment of papillary muscles following ventricular septal myectomy. Circulation 1974;50:II181-II188.

10. Jebara VA, Mihaileanu S, Acar C, et al. Left ventricular outflow tract obstruction after mitral valve repair. Results of the sliding leaflet technique. Circulation 1993;88:II30-II34.

11. Wan CK, Dearani JA, Sundt TM 3rd, et al. What is the best surgical treatment for obstructive hypertrophic cardiomyopathy and degenerative mitral regurgitation? Ann Thorac Surg 2009;88:727-31; discussion 731-2.

12. Nishimura RA, Holmes DR Jr. Clinical practice. Hypertrophic obstructive cardiomyopathy. N Engl J Med 2004:350:1320-7.

13. Gersh BJ, Maron BJ, Bonow RO, et al. ACCF/AHA guideline for the diagnosis and treatment of hypertrophic cardiomyopathy: a report of the American College of Cardiology Foundation/American Heart Association Task Force on Practice Guidelines. American College of Cardiology Foundation/American Heart Association Task Force on Practice; American Association for Thoracic Surgery; American Society of Echocardiography; American Society of Nuclear Cardiology; Heart Failure Society of America; Heart Rhythm Society; society for Cardiovascular Angiography and Interventions; Society of Thoracic Surgeons. J Thorac Cardiovasc Surg 2011;142:e153-e203. 
14. Lakkis NM, Nagueh SF, Dunn JK, et al. Nonsurgical septal reduction therapy for hypertrophic obstructive cardiomyopathy: one-year follow-up. J Am Coll Cardiol 2000;36:852-5.

15. Ommen SR, Maron BJ, Olivotto I et al. Long-term effects of surgical septal myectomy on survival in patients with obstructive hypertrophic cardiomyopathy. J Am Coll Cardiol 2005;46:470-6.

16. Maron BJ. Controversies in cardiovascular medicine. Surgical myectomy remains the primary treatment option for severely symptomatic patients with obstructive hypertrophic cardiomyopathy. Circulation 2007;116:196206; discussion 206.

17. Sorajja P, Valeti U, Nishimura RA et al. Outcome of alcohol septal ablation for obstructive hypertrophic cardiomyopathy. Circulation 2008;118:131-9.

18. Maron BJ. Commentary and re-appraisal: surgical septal myectomy vs. alcohol ablation: after a decade of controversy and mismatch between clinical practice and guidelines. Prog Cardiovasc Dis 2012;54:523-8.

19. Chang SM, Lakkis NM, Franklin J, et al. Predictors of outcome after alcohol septal ablation therapy in patients with hypertrophic obstructive cardiomyopathy. Circulation 2004;109:824-7.

20. ElBardissi AW, Dearani JA, Nishimura RA, et al. Septal myectomy after previous septal artery ablation in hypertrophic cardiomyopathy. Mayo Clin Proc 2007;82:1516-22.

21. Schaff HV, Brown ML, Dearani JA, et al. Apical myectomy: a new surgical technique for management of severely symptomatic patients with apical hypertrophic cardiomyopathy. J Thorac Cardiovasc Surg 2010;139:634-40.

22. Maron BJ, Roberts WC, Edwards JE, et al. Sudden death in patients with hypertrophic cardiomyopathy: characterization of 26 patients with functional limitation.
Am J Cardiol 1978;41:803-10.

23. McKenna W, Deanfield J, Faruqui A, et al. Prognosis in hypertrophic cardiomyopathy: role of age and clinical, electrocardiographic and hemodynamic features. Am J Cardiol 1981;47:532-8.

24. Altarabsheh SE, Dearani JA, Burkhart HM, et al. Outcome of septal myectomy for obstructive hypertrophic cardiomyopathy in children and young adults. Ann Thorac Surg 2013;95:663-39; discussion 669.

25. Schaff HV, Dearani JA, Ommen SR, et al. Expanding the indications for septal myectomy in patients with hypertrophic cardiomyopathy: results of operation in patients with latent obstruction. J Thorac Cardiovasc Surg 2012;143:303-9.

26. Williams WG, Rebeyka IM. Surgical intervention and support for cardiomyopathies of childhood. Prog Pediatr Cardiol 1992;1:61-71.

27. Minakata K, Dearani JA, Schaff HV, et al. Mechanisms for recurrent left ventricular outflow tract obstruction after septal myectomy for obstructive hypertrophic cardiomyopathy. Ann Thorac Surg 2005;80: 851-6.

28. McCann GP, Van Dockum WG, Beek AM, et al. Extent of myocardial infarction and reverse remodeling assessed by cardiac magnetic resonance in patients with and without right bundle branch block following alcohol septal ablation for obstructive hypertrophic cardiomyopathy. Am J Cardiol 2007;99:563-7.

29. McCully RB, Nishimura RA, Tajik AJ, et al. Extent of clinical improvement after surgical treatment of hypertrophic obstructive cardiomyopathy. Circulation 1996;94:467-71.

30. Said SM, Schaff HV, Abel MD, et al. Transapical approach for apical myectomy and relief of midventricular obstruction in hypertrophic cardiomyopathy. J Card Surg 2012;27:443-8.
Cite this article as: Kotkar KD, Said SM, Dearani JA, Schaff HV. Hypertrophic obstructive cardiomyopathy: the Mayo Clinic experience. Ann Cardiothorac Surg 2017;6(4):329-336. doi: 10.21037/acs.2017.07.03 